\title{
MODELOS TURÍSTICOS LOCALES. ANÁLISIS COMPARADO DE DOS DESTINOS DE LA COSTA BLANCA
}

\author{
Carlos Javier Baños Castiñeira
}

\section{RESUMEN}

La escala local se muestra como la más adecuada para el análisis de los destinos turísticos, dada la importancia que las estructuras municipales han tenido en la configuración de los mismos. Asimismo, el grado de madurez alcanzado por estos destinos turísticos, adscritos al denominado modelo turístico de sol y playa masivo, aconseja implementar importantes procesos de reestructuración para afrontar los retos de la competitividad y sostenibilidad futura de la actividad, procesos en los que el municipio ha de tener un papel fundamental. Por otra parte, diferencias respecto a los agentes que han liderado el proceso de creación del espacio turístico, el grado de planificación con el que se desarrolló ese proceso o la estructura de la propiedad de la tierra han supuesto la generación de distintos modelos turísticos locales, con perspectivas y retos de futuro diferentes.

Palabras clave: escala local, destino-municipio turístico, modelos turísticos, reestructuración de áreas turísticas maduras.

\section{RÉSUMÉ}

L'échelle local est la plus assortissante pour l'analyse des destins touristiques, pour l'importance des structures municipaux à la configuration des mêmes. Aussi, l'apuisement de ces destins touristiques balneaires, il faut de développer des procedures pour affronter les défis futures, oú la municipalité aura une importante position. Pareillement, des différences sur le rôle des agents qui ont fait l'espace touristique, la planification ou la spontanéite comment se développe ces processus et la structure de la propriété du sol ont crée modéles touristiques locaux différents, avec distinctes perspectives de future.

Mots clefs: échelle local, destin-municipalité touristique, modéles touristiques, recomposition d'espaces touristiques épuisés.

Las relaciones entre municipio y la actividad turística, la asimilación entre entidades locales y los destinos turísticos, son asuntos que cobran gran vigencia en la provincia de Alicante, tras la reciente aprobación de la Ley de Turismo de la Comunidad Valenciana, 
donde se contempla la declaración de municipios turísticos y que debería tener importantes consecuencias sobre la gestión y la calidad del destino turístico, entendido éste de una forma global.

La escala local se presenta como la más apropiada para el análisis de los destinos turísticos adscritos al modelo de sol y playa masivo debido a la importancia que en la configuración de los mismos han tenido las estructuras preturísticas locales, los agentes económicos actuantes y el marco jurídico administrativo que otorga, en el caso español, al municipio importantes competencias en materia de planeamiento urbanístico. Asimismo, dada la fase en la que se encuentra el turismo litoral, interpretado a través del conocido modelo de Ciclo de vida de los destinos turísticos (BUTLER, 1980), los aspectos de gestión del turismo precisos para el mantenimiento futuro de la actividad son, en alto grado, competencia de la administración local. No obstante, la realidad turística que viene configurándose desde finales de la década de los años ochenta exige paralelamente al análisis local, desde el punto de vista de la gestión territorial y ambiental, de un análisis multiescalar que establezca las bases de la coordinación y articulación entre diferentes escalas espaciales y los correspondientes entes administrativos responsables. En este sentido, Vera, Palomeque, Marchena y Antón indican la existencia de, al menos, cuatro marcos de referencia espacial, (a las que, posiblemente, cabría añadir, con una perspectiva de escenarios futuros, la europea); la escala estatal, responsabilidad de la administración central; la regional, coincidente con el ámbito de actuación de las Comunidades Autónomas; escalas intermedias (subregionales, comarcales, supramunicipales) en las que los problemas de coordinación, gestión y articulación se acentúan, al tratarse éste de un ámbito donde la administración no actúa de manera obligatoria, pero que, sin embargo, posee un carácter estratégico ante los nuevos procesos de cualificación de los destinos turísticos que se hallan en la fase de madurez, según el referido modelo de Ciclo de vida de los destinos turísticos; finalmente, la escala local que corresponde, en clave administrativa, al municipio, y es objeto de análisis más profundo en el presente artículo.

Ejemplos de coordinación entre las diferentes escalas administrativas y su plasmación territorial se encuentra en los Planes de Excelencia del Plan Futures donde el impulso dado desde la administración turística estatal (Ministerio de Comercio y Turismo) ha catalizado la puesta en marcha de diversas actuaciones promovidas por entidades locales o Comunidades Autónomas, con fines de reestructuración y cualificación de los espacios turísticos, e incluso, en algún caso, se puede hablar de reconversión turística. Precisamente, han sido aspectos de falta de coordinación entre distintos departamentos de la administración los que han influido en el fracaso de alguna de estas acciones. Así ocurrió en el caso de Torremolinos, donde las actuaciones realizadas por el MOPTMA, concretamente en el paseo marítimo de la Carihuela, no se hallaban subrogadas a las directrices del Plan de Excelencia Turística lo que supuso el enfrentamiento con la sociedad local, el empresariado y los responsables municipales (CONSULTUR, 1996).

En sentido contrario, la inexistencia de estructuras administrativas que den carta de naturaleza a verdaderas realidades turísticas, tiene buen reflejo en las escalas intermedias. Así, por ejemplo, la situación del traspaís del litoral norte de la provincia de Alicante, paulatinamente incorporado a la oferta turística de uno de los más importantes destinos del Mediterráneo, Benidorm, deja patente esa falta de consideración hacia las escalas espaciales subregionales, supramunicipales. En efecto, Benidorm y los municipios de su entorno han puesto en funcionamiento, desde sus respectivos ayuntamientos, convenios de colaboración que afectan fundamentalmente a la promoción de los recursos de esos municipios interiores, incorporados como elementos de oferta del destino Benidorm, (Jalón, Benissa, Guadalest, Callosa d'En Sarrià). En definitiva, se conforma un producto turístico, que 
afecta territorialmente a un ámbito mayor que el del municipio e inferior, de menor rango espacial, al de la región o la Comunidad Autónoma. Se trata éste de un aspecto recogido por la administración autonómica en el título cuarto de la reciente Ley de Turismo de la Comunidad Valenciana (Bases para la ordenación de los espacios turísticos) donde se incorporan las conclusiones elaboradas a partir de los estudios previos realizados para la redacción de las Bases del Plan Director de los Espacios Turísticos de la Comunidad Valenciana.

La Ley 3/1998, de 21 de mayo, de la Generalitat Valenciana, de Turismo de la Comunidad Valenciana, pretende establecer las bases que permitan compensar los déficits financieros adquiridos por los ayuntamientos al asumir la tarea de responder a las necesidades de la población no residente. Es competencia municipal la gestión de variados elementos que, como muestra del carácter integral que posee un destino turístico en cuanto a los componentes que lo conforman, son claves para su adecuado funcionamiento. Así, la gestión de equipamientos culturales y deportivos, del patrimonio histórico y cultural, infraestructuras y servicios varios (recogida de basuras, transporte urbano), el urbanismo o la protección medioambiental, son aspectos que si poseen gran importancia para municipios no turísticos, innegablemente son trascendentales para un municipio que tiene en el turismo su actividad económica principal, más aún si cabe al considerar el incremento en las exigencias de calidad en la experiencia turística por parte de importantes segmentos de demanda.

Exigencia previa a la puesta en marcha de las acciones consideradas en esta Ley de Turismo de la Comunidad Valenciana es la delimitación de los municipios que serán objeto de esta ley; en definitiva, la definición de aquellos criterios que permitan identificar un municipio turístico. En este sentido, la Ley 3/1998 utiliza dos indicadores básicos, número de visitantes que recibe una población y capacidad de alojamiento. De esta manera, según el volumen de afluencia de los visitantes y la relación entre el alojamiento turístico y el de primeras residencias, se distinguen tres supuestos o tipologías de municipios turísticos:

- Destino turístico

- Destino vacacional

- Destino de atracción turística

Efectivamente, los criterios demográficos y de capacidad de acogida, en función exclusivamente del alojamiento, parecen válidos para identificar las diferencias entre municipios en los que el turismo se ha configurado como actividad estratégica en sus economías pero mantienen dinámicas diferenciadas. Sin embargo, no son éstos los únicos indicadores que permiten discernir el grado de especialización turística de un destino/municipio turístico, las diferencias de sus dinámicas socioeconómicas o la diversidad que en su plasmación sobre el territorio ha propiciado esa actividad.

Las notables diferencias existentes entre modelos turísticos se ponen claramente de manifiesto mediante el análisis de cinco indicadores básicos, componentes del sistema turístico local. Asimismo, el recurso a esos indicadores permite identificar las debilidades y oportunidades de los modelos turísticos desarrollados y formular una serie de propuestas de actuación que incidan sobre la viabilidad futura de la actividad turística a escala local.
a.- Volumen de oferta y estructura del alojamiento
b.- Modelos urbanos generados
c.- Estacionalidad
d.- Función comercial y ofertas complementarias
e.- Estructura demográfica 
A pesar de la necesidad metodológica de individualizar el análisis de cada uno de estos componentes, es necesario indicar el alto grado de interrelación y dependencia existente entre sí. Así, resultaría imposible entender el modelo de ciudad de Benidorm sino es a partir del tipo de alojamiento que posee o del potente aparato comercial existente $\mathrm{y}$, al mismo tiempo, la hotelería y el comercio de este destino se consolida gracias al sustrato urbano sobre el que se asientan.

En el presente artículo se pretende, partiendo del análisis de los cinco indicadores señalados, poner de manifiesto las importantes diferencias que existen entre los dos núcleos turísticos valencianos más importantes, las poblaciones de Torrevieja y Benidorm ${ }^{1}$. Estos dos municipios de la Costa Blanca tienen, sobre el origen común de la explotación de los tradicionales recursos sol y playa, en la actividad turística la base de sus economías y cuentan con el mayor volumen de oferta de alojamiento instalada de los destinos valencianos. Sin embargo, esta actividad posee diferentes connotaciones para uno u otro destino. Así, se ha definido el modelo turístico torrevejense como de filiación inmobiliario-turística, donde la construcción y sus servicios auxiliares se han configurado como los verdaderos motores económicos municipales, mientras que, para el caso de Benidorm, los principales subsectores de actividad corresponden con las actividades comerciales y de servicios al consumidor final (cuadro 1).

\section{Cuadro 1}

NÚMERO DE IMPUESTOS DE ACTIVIDADES ECONÓMICAS SEGÚN DIVISIÓN DE ACTIVIDAD EN LOS MUNICIPIOS DE TORREVIEJA Y BENIDORM

\begin{tabular}{|c|c|c|c|c|c|c|c|c|c|c|c|}
\hline & IAE 0 & IAE 1 & IAE 2 & IAE 3 & IAE 4 & IAE 5 & IAE 6 & IAE 7 & IAE 8 & IAE 9 & TOTAL \\
\hline BENIDORM & 0 & 1 & 1 & 14 & 73 & 334 & 2896 & 328 & 377 & 463 & 4487 \\
\hline$\%$ & 0 & 0,02 & 0,02 & 0,31 & 1,63 & 7,44 & 64,54 & 7,31 & 8,40 & 10,32 & \\
\hline TORREVIEJA & 0 & 4 & 11 & 29 & 78 & 442 & 1490 & 145 & 419 & 277 & 2895 \\
\hline$\%$ & 0 & 0,14 & 0,38 & 1,00 & 2,69 & 15,27 & 51,47 & 5,01 & 14,47 & 9,57 & \\
\hline
\end{tabular}

Fuente: Listado de Número de IAE por Municipio y Epígrafe. Cámara Oficial de Comercio, Industria y Navegación de Alicante.

Elaboración propia.

Denominación de las Divisiones de Actividades del IAE.

IAE 0: Ganadería independiente.

IAE 1: Energía y agua.

IAE 2: Extracción y transformación de minerales no energéticos y productos derivados. Industria química.

IAE 3: Industrias transformadoras de los metales. Mecánica de precisión.

IAE 4: Otras industrias manufactureras.

IAE 5: Construcción.

IAE 6: Comercio, restaurantes y hospedaje. Reparaciones.

IAE 7: Transporte y comunicaciones.

IAE 8: Instituciones financieras, seguros, servicios prestados a las empresas y alquileres.

IAE 9: Otros servicios.

1 Entre ambos destinos acumulan más de 400.000 plazas de alojamiento no permanente. 
Partiendo de bases similares, la actividad turística ha evolucionado de manera bien distinta en cada uno estos municipios debido a factores tales como los diferentes agentes actuantes o el grado de planificación implementado en el diseño de los modelos urbanos. De esta manera se constata una importante diversidad interna manifestada en los distintos modelos territoriales-turísticos generados (concentrado en Benidorm, extensivo en Torrevieja), la estructura de la oferta de alojamiento, las ofertas comerciales y de ocio o en la estacionalidad de los flujos de visitantes.

\section{Estructura de la oferta de alojamiento}

No cabe duda que la existencia de una importante planta de alojamiento es uno de los factores fundamentales que identifican a un municipio o destino como turístico. Así, por ejemplo, los municipios litorales de la Costa Blanca, sin excepción, poseen una capacidad de alojamiento muy superior a la necesaria si se considerara únicamente la normal evolución demográfica de la población residente ${ }^{2}$.

Sin embargo, el criterio del alojamiento no ha de tener una consideración únicamente cuantitativa. Las diferencias en cuanto a la estructura del alojamiento, atendiendo a criterios de tipología y calidad, pueden generar importantes consecuencias para un destino turístico, pues afectará de manera fundamental al tipo de demanda potencialmente captable, al modelo urbano-turístico o al aparato comercial instalado.

Cuadro 2

NÚMERO DE PLAZAS DE ALOJAMIENTO EN LOS MUNICIPIOS DE BENIDORM Y TORREVIEJA

\begin{tabular}{|l|c|c|c|c|c|c|c|}
\hline & \multicolumn{2}{|c|}{$\begin{array}{c}\text { PLAZAS EN HOTELES } \\
\text { Y HOSTALES }\end{array}$} & \multicolumn{2}{|c|}{$\begin{array}{c}\text { PLAZAS EN } \\
\text { VIVIENDA }\end{array}$} & \multicolumn{2}{c|}{ PLAZAS EN CAMPING } & \multirow{2}{*}{$\begin{array}{c}\text { TOTAL } \\
\text { PLAZAS }\end{array}$} \\
\cline { 2 - 7 } & TOTAL & $\%$ & TOTAL & $\%$ & TOTAL & $\%$ & \\
\hline BENIDORM & 33.687 & 22,7 & 109.412 & 73,7 & 5.213 & 3,5 & 148.312 \\
\hline TORREVIEJA & 1.551 & 0,71 & 213.500 & 98,73 & 1.227 & 0,56 & 216.278 \\
\hline
\end{tabular}

Fuente: Fundación Cavanilles de Altos Estudios Turísticos, 1996, Agencia Valenciana del Turismo, 1997 y Ayuntamiento de Torrevieja.

Elaboración propia.

Cuadro 3

DISTRIBUCIÓN DE LAS PLAZAS HOTELERAS DE BENIDORM Y TORREVIEJA SEGÚN CATEGORÍA (ESTRELLAS ORO)

\begin{tabular}{|l|c|c|c|c|c|c|c|c|c|}
\hline & \multicolumn{2}{|c|}{ 4 ESTRELLAS } & \multicolumn{2}{c|}{ 3 ESTRELLAS } & \multicolumn{2}{c|}{ 2 ESTRELLAS } & \multicolumn{2}{c|}{ 1 ESTRELLA } & \multirow{2}{*}{ TOTAL } \\
\cline { 2 - 9 } & TOTAL & $\%$ & TOTAL & $\%$ & TOTAL & $\%$ & TOTAL & $\%$ & \\
\hline BENIDORM & 2.999 & 9,36 & 20.484 & 61,72 & 8.733 & 26,31 & 972 & 2,92 & 33.188 \\
\hline TORREVIEJA & 0 & 0 & 287 & 19,51 & 1.080 & 73,41 & 104 & 7,07 & 1.471 \\
\hline
\end{tabular}

Fuente: Agencia Valenciana del Turismo, 1997.

Elaboración propia.

2 El parque de viviendas de uso estacional, no permanente, en los municipios litorales de la provincia de Alicante supone el $65 \%$ del total, mientras que en los municipios interiores no alcanza el $35 \%$. 
DISTRIBUCIÓN DE LAS PLAZAS EN VIVIENDA SEGÚN CATEGORÍAS EN BENIDORM Y TORREVIEJA ${ }^{3}$

\begin{tabular}{|l|c|c|c|c|c|}
\hline \multirow{2}{*}{ BENIDORM } & \multicolumn{2}{|c|}{ PRIMERA CATEGORÍA } & \multicolumn{2}{c|}{ SEGUNDA CATEGORÍA } & \multirow{2}{*}{ TOTAL } \\
\cline { 2 - 5 } & TOTAL & $\%$ & TOTAL & $\%$ & \\
\hline TORREVIEJA & 2.342 & 12,06 & 17.070 & 87,84 & 19.412 \\
\hline
\end{tabular}

Fuente: Agencia Valenciana del Turismo, 1997.

Elaboración propia.

\section{Cuadro 5}

PLAZAS POTENCIALES DE ALOJAMIENTO EN VIVIENDAS EN BENIDORM Y TORREVIEJA. DISTRIBUCIÓN REGLADA-NO REGLADA ${ }^{4}$

\begin{tabular}{|l|c|c|c|c|c|}
\hline \multirow{2}{*}{ BENIDORM } & \multicolumn{2}{|c|}{ PLAZAS LEGALES } & \multicolumn{2}{c|}{ PLAZAS ALEGALES } & \multirow{2}{*}{ TOTAL } \\
\cline { 2 - 5 } & TOTAL & $\%$ & TOTAL & $\%$ & \\
\hline TORREVIEJA & 19.412 & 16,07 & 90.000 & 83,93 & 109.412 \\
\hline
\end{tabular}

Fuente: Agencia Valenciana del Turismo, Fundación Cavanilles de Altos Estudios Turísticos y Ayuntamiento de Torrevieja.

Elaboración propia.

Cuadro 6

DISTRIBUCIÓN DE LAS PLAZAS DE ALOJAMIENTO EN BENIDORM Y TORREVIEJA SEGÚN TIPO DE GESTIÓN (Comercial-No comercial)

\begin{tabular}{|l|c|c|c|c|c|}
\hline \multirow{2}{*}{} & \multicolumn{2}{|c|}{$\begin{array}{c}\text { PLAZAS DE GESTIÓN } \\
\text { COMERCIAL }\end{array}$} & \multicolumn{2}{c|}{$\begin{array}{c}\text { PLAZAS DE GESTIÓN } \\
\text { NO COMERCIAL }\end{array}$} & \multirow{2}{*}{ TOTAL } \\
\cline { 2 - 5 } & TOTAL & $\%$ & TOTAL & $\%$ & \\
\hline BENIDORM & 58.312 & 37,82 & 90.000 & 62,18 & 148.312 \\
\hline TORREVIEJA & 4.747 & 2,11 & 211.531 & 97,89 & 216.278 \\
\hline
\end{tabular}

Fuente: Conselleria de Industria y Comercio, Agencia Valenciana del Turismo, Fundación Cavanilles de Altos Estudios Turísticos y Ayuntamiento de Torrevieja.

Elaboración propia.

Resultan obvias las diferencias de la estructura de la oferta de alojamiento entre ambos destinos. Si bien tanto Torrevieja como Benidorm concentran la mayor parte de esta oferta en la modalidad de vivienda, la diferencia en cuanto a la planta hotelera es verdaderamente significativa. El volumen de plazas hoteleras de Benidorm sitúa a este destino turístico

3 Se indican los datos de Unidades de Alojamiento Turístico (UAT) inscritos en el Registro de Empresas explotadoras de apartamentos turísticos, de la Agencia Valenciana del Turismo, a fecha de diciembre de 1997.

4 La consideración de plaza reglada viene dada por la inclusión en el anteriormente citado Registro de Empresas explotadoras de apartamentos turísticos. 
entre los más importantes del Mediterráneo Occidental ${ }^{5}$. Este tipo de alojamiento de carácter comercial y reglado permite una mayor profundización en los mercados a través de los canales de comercialización convencionales. Por otro lado, la demanda hotelera posee hábitos de consumo y ocio particulares, con un mayor nivel de gasto en diversiones y oferta complementaria en comparación con segmentos vacacionales que mantienen hábitos de consumo próximos a los urbanos convencionales.

La gestión comercial de las plazas de alojamiento no se limita en Benidorm a los establecimientos hoteleros. Más de diecinueve mil plazas en apartamentos son plazas regladas, que si bien no representan siquiera el veinte por ciento del total, superan con mucho las del resto de los municipios turísticos de la provincia de Alicante. De esta forma, en el año 1997, se realizaron 4.019.445 pernoctaciones en este tipo de alojamiento. Por el contrario, en Torrevieja, en 1997 existían 524 viviendas contabilizadas como alojamientos turísticos sobre un total censado de 61.000 viviendas de temporada, ocupadas en régimen de alquiler o en propiedad.

En la actualidad una de los principales empeños de la administración turística valenciana es progresar en la regulación de la oferta de alojamiento no reglada o de gestión no comercial, constituida por lo general por alojamientos en vivienda (apartamentos, bungalows) en régimen de alquiler y que, salvo en casos aislados de indudable calidad, únicamente genera beneficios de tipo inmobiliario, pero no propicia la optimización turística de ese volumen de plazas, ya que la dificultad de su comercialización a través de los canales habituales es muy elevada, lo que viene a afectar a la ocupación estacional de las mismas, limitada a los meses de temporada alta. Asimismo, el carácter alegal de ese alojamiento incide directamente sobre la calidad del mismo así como sobre la imagen global del destino, además de otras implicaciones como la fiscalidad o la competencia desleal con empresas de carácter estrictamente turístico. En definitiva, afecta a la capacidad de dotar al sector de un nuevo marco, debido a las trabas que este tipo de oferta supone para la redefinición de los destinos turísticos en consonancia con las nuevas tendencias de la demanda (VERA REBOLLO, CRUZ OROZCO y BAÑOS CASTIÑEIRA, 1995).

\section{Modelos urbanos}

Los municipios de Benidorm y Torrevieja son ejemplo de dos modelos distintos de ocupación del territorio para un uso urbano-turístico; un modelo concentrado, el de Benidorm, y otro definido como extensivo, claramente manifestado en el caso de Torrevieja.

Las causas de la diferente plasmación territorial del hecho turístico en ambos destinos se encuentran en la forma en que se desarrolla el proceso de creación del espacio turístico, a partir de las bases preexistentes y en los diferentes agentes actuantes.

En Torrevieja, factores como la importancia que tradicionalmente ha tenido la explotación salinera en cuanto a volumen de empleo y actividad económica, la permanencia de la actividad pesquera hasta inicios la década de los años ochenta, la presencia de la navegación comercial hasta los años sesenta o la existencia de una agricultura de secano de bajo rendimiento, fueron las condiciones que crearon un escenario donde destacaba la falta de iniciativas y cultura empresarial, de manera que se consideraba a la actividad turística como un complemento de esas actividades tradicionales, en contraste con la situación de Benidorm donde el dinamismo empresarial y la apuesta decidida por el turismo ha sido uno de los factores fundamentales que explican la actual situación de la ociurbe de la Marina

5 En 1997, 1.022.768 visitantes se alojaron en hoteles de Benidorm, generando 9.450 .847 pernoctaciones (Fuente: Ayuntamiento de Benidorm). 

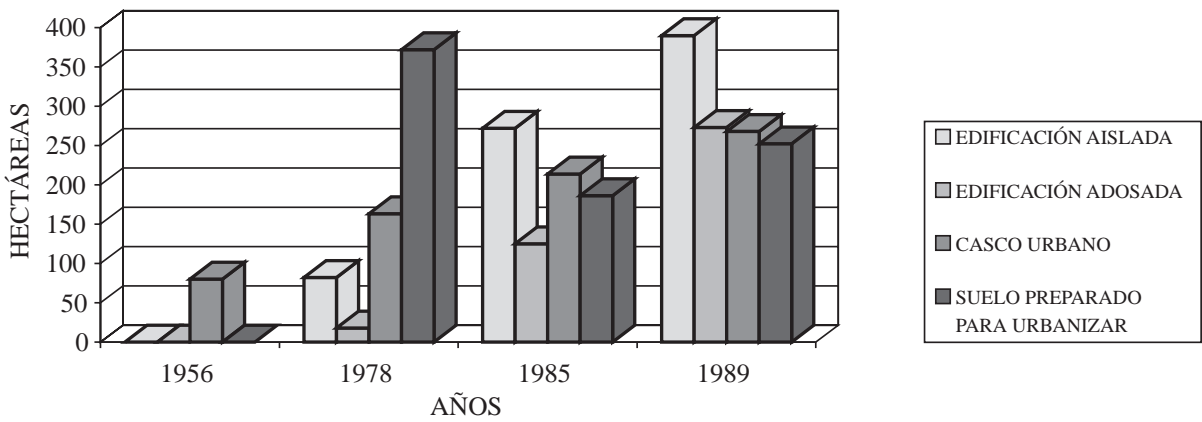

FIGURA 1. Evolución de la superficie de suelo construida en el municipio de Torrevieja según tipología de la edificación.

Fuente: Torres Alfosea, F.

Baja. El definitivo desmantelamiento de esas ocupaciones y la entrada de capital extracomarcal supuso la afectación hacia el uso residencial de los antiguos espacios agrarios, transformados en grandes asentamientos urbano turísticos. A partir de ese momento el desarrollo urbano de Torrevieja queda en manos de las promotoras inmobiliarias, mientras la administración local queda relegada al papel de recaudador de los impuestos generados por la actividad inmobiliaria (licencias de obra, IBI).

Inicialmente la tipología edificatoria habitual fue la edificación aislada, caso de una de las primeras urbanizaciones construidas, Villa Sol. Posteriormente se produce el desarrollo de la edificación adosada que supondrá la compactación urbanística del municipio, de tal manera que Torrevieja cuenta actualmente con tres únicos espacios libres abiertos al mar, la finca Lo Ferrís al sur municipal, El Molino en la playa de La Mata (TORRES ALFOSEA, 1995) y un tercer espacio, situado entre el sector sur de Cabo Cervera y la Punta del Salaret, constituido por siete calas, tres de las cuales mantiene un acceso libre desde el interior.

El caso de la ciudad de Benidorm es completamente distinto del resto de los municipios litorales de la provincia de Alicante. Benidorm fue planificada urbanísticamente para su despegue turístico y el posterior desarrollo estuvo guiado por los mismos propietarios del suelo, en muchos casos convertidos en hoteleros.

El Plan General de Ordenación Urbana de Benidorm, aprobado en 1956, marcó las líneas del desarrollo urbano que debería definir el futuro Benidorm. Sin embargo, las propuestas iniciales de ese P.G.O.U. no pudieron, en muchos casos, llevarse a buen término. La fuerte presión de la demanda generó, ya en los años sesenta, la escasez de suelo urbanizable, que derivó en un intenso proceso especulativo e incremento de las volumetrías constructivas.

El análisis del planeamiento urbanístico vigente (cuadro 7) es fiel reflejo de la disparidad entre ambos modelos. Torrevieja presenta una mayor tendencia hacia el consumo de su territorio con fines residenciales. La extensividad y compactación del espacio urbanoturístico torrevejense queda patente tanto en lo que se refiere al suelo consolidado como en las expectativas futuras de crecimiento, con casi ochocientas hectáreas clasificadas como urbanizables. Es necesario poner de manifiesto que mientras Torrevieja apenas posee ya una reserva de suelo sin urbanizar (el 85\% del suelo urbanizable corresponde al Parque Natural de las Salinas de Torrevieja y La Mata), Benidorm mantiene casi el 60\% de su suelo como no urbanizable, con lo que se mantienen opciones de futuras actuaciones de cualificación del destino. 


\section{Cuadro 7}

SUPERFICIES DE SUELO CLASIFICADO SEGÚN PLANEAMIENTO URBANÍSTICO

VIGENTE EN BENIDORM Y TORREVIEJA ${ }^{6}$

(superficies expresadas en hectáreas)

\begin{tabular}{|l|c|c|c|c|c|c|c|c|}
\hline & \multicolumn{2}{|c|}{ S.U. } & \multicolumn{2}{c|}{ S.U.P. } & \multicolumn{2}{c|}{ S.U.N.P. } & \multicolumn{2}{c|}{ S.N.U. } \\
\hline & Total & $\%$ & Total & $\%$ & Total & $\%$ & Total & $\%$ \\
\hline BENIDORM & 869,46 & 26,04 & 434,07 & 12,05 & 148,10 & 4.26 & $2.020,36$ & 58,2 \\
\hline TORREVIEJA & $1.286,43$ & 19,73 & 531,53 & 8,15 & 254,10 & 3,9 & $4.448 *$ & 68,22 \\
\hline
\end{tabular}

Fuente: Comisión Provincial de Urbanismo de Alicante.

Elaboración propia.

* 3.754 hectáreas corresponden al Parque Natural de las Lagunas de la Mata y Torrevieja, de gestión autonómica.

Las importantes diferencias entre la extensividad del poblamiento turístico de Torrevieja y la concentración que caracteriza Benidorm se ponen nuevamente de manifiesto al comparar las entidades de población existentes y sus viviendas no principales en ambos municipios, pues Benidorm concentra casi el cien por cien del parque de viviendas de potencial uso turístico en el núcleo urbano, mientras en Torrevieja existen más de noventa entidades, aglutinadas en el siguiente cuadro en seis, al margen del núcleo tradicional, que concentran más del cuarenta por ciento del volumen de plazas.

Cuadro 8

ENTIDADES DE POBLACIÓN Y NÚMERO DE VIVIENDAS NO PRINCIPALES EN LOS MUNICIPIOS DE BENIDORM Y TORREVIEJA

\begin{tabular}{|c|c|c|c|c|c|}
\hline MUNICIPI0 & ENTIDADES DE POBLACIÓN & $\begin{array}{c}\text { NÚMER0 DE } \\
\text { VIVIENDAS } \\
\text { N0 } \\
\text { PRINCIPALES }\end{array}$ & MUNICIPI0 & $\begin{array}{c}\text { ENTIDADES } \\
\text { DE } \\
\text { POBLACIÓN }\end{array}$ & $\begin{array}{c}\text { NÚMER0 DE } \\
\text { VIVIENDAS } \\
\text { N0 } \\
\text { PRINCIPALES }\end{array}$ \\
\hline \multirow[t]{8}{*}{ TORREVIEJA } & LA MATA & 1.1714 & \multirow[t]{8}{*}{ BENIDORM } & ALMAFRA & 5 \\
\hline & LOS BALCONES & 2.004 & & BENIDORM & 31.827 \\
\hline & CABO CERVERA-PL. DE LA MATA & 6.547 & & COBLANCA & 147 \\
\hline & EL CHAPARRAL & 4.300 & & DISEMINADO & 347 \\
\hline & PUNTA PRIMA & 2.343 & & & \\
\hline & LAS TORRETAS & 2.908 & & & \\
\hline & TORREVIEJA & 24.509 & & & \\
\hline & DISEMINADO & 19 & & & \\
\hline
\end{tabular}

Fuente: Censos de Población y viviendas 1991. Nomenclátor de las Ciudades, Villas, Lugares, Aldeas y demás Entidades de Población con especificación de sus núcleos. Alicante. Instituto Nacional de Estadística. 1993. Elaboración propia.

6 Los documentos de planeamiento urbanístico a los que se hace referencia son: Plan General de Ordenación urbana de Benidorm, aprobado el 25 de julio de 1990 y el Plan General de Ordenación urbana de Torrevieja, aprobado el 22 de diciembre de 1986. 
Las implicaciones de los distintos modelos de organización espacial del desarrollo urbano-turístico son varias y afectan en gran medida al consumo de importantes recursos territoriales como el suelo y el agua.

El modelo extensivo, ejemplificado en Torrevieja, genera una mayor presión sobre el suelo, tal y como se ha señalado. Ese desarrollo laxo, da lugar a importantes deseconomías en lo que a las infraestructuras básicas se refiere, pues requiere unas redes de mayor extensión, lo que complica la gestión de las mismas. Los efectos sobre los recursos hídricos son varios (VERA REBOLLO, J.F. y RICO AMORÓS, A. 1995).

- la mayor superficie de espacio construido obliga a la existencia de redes de abastecimiento de agua y saneamiento de mayor extensión, lo que supone el incremento de las pérdidas en transporte y complica las reparaciones. Sin embargo, el problema de las pérdidas en red puede solucionarse con una gestión adecuada (prueba de ello son muchos municipios de la provincia, y concretamente el de Torrevieja, que al ceder la gestión del abastecimiento a manos de empresas especializadas, han reducido de manera espectacular estas mermas).

- en muchas ocasiones, las urbanizaciones carecen de red de saneamiento. De esta forma proliferan los pozos ciegos o fosas sépticas, que son focos de contaminación de acuíferos y del propio medio marino. En el municipio de Torrevieja se ha realizado un importante esfuerzo en este sentido y, tal y como manifestó el director de la Estación Depuradora de Aguas Residuales en entrevista personal, sólo una de las urbanizaciones resta sin conectar a la red de saneamiento.

- infraestructuras sobredimensionadas para poder atender la demanda generada en las fechas punta y que permanecen subutilizadas el resto del año.

Asimismo, la extensividad del desarrollo urbano torrevejense, realizado mediante la proliferación de urbanizaciones, ha provocado importantes problemas de accesibilidad y conectividad entre las mismas así como la exigencia del trazado de una red caminera de gran longitud, costosa en su mantenimiento, y déficits en lo relativo a equipamientos urbanos, dotaciones o espacios libres.

Por oposición a lo anteriormente señalado para modelos laxos, los modelos urbanos concentrados facilitan una mayor racionalización en la gestión de los recursos y, no cabe duda, en la provincia de Alicante es Benidorm el ejemplo prototípico. Asimismo, se concentran los impactos sobre el territorio, lo que permite que Benidorm mantenga buena parte de su espacio municipal como reserva para futuras actuaciones.

Uno de los aspectos más característicos de la escena urbana de Benidorm es, efecto de esa concentración del modelo urbano-turístico, el crecimiento en altura de sus edificios, proceso obligado por los altos precios del suelo. Las Zonas de Edificación Abierta, aquellas con edificación libre, corresponden a los ensanches yuxtapuestos al casco antiguo y que se desarrollan paralelos a las playas de Poniente y Levante así como la zona lindante con el área de La Cala de Finestrat y las estribaciones de Sierra Helada ${ }^{7}$. Es este sector el que confiere la imagen más difundida de la ciudad, con una importante presencia del uso hotelero.

Precisamente, este tipo de desarrollo urbano es la causa de una de las principales críticas que se vierten para estos modelos, la gran densidad urbana da lugar a efectos de pantalla que en el caso de Benidorm no permiten la visión de la ribera del mar desde el interior y dan impresión de gran congestión.

7 En este último caso el P.G.O.U. indica que las nuevas actuaciones a desarrollar lo harán a partir de un Estudio de Detalle de la zona, dadas sus peculiaridades topográficas. 


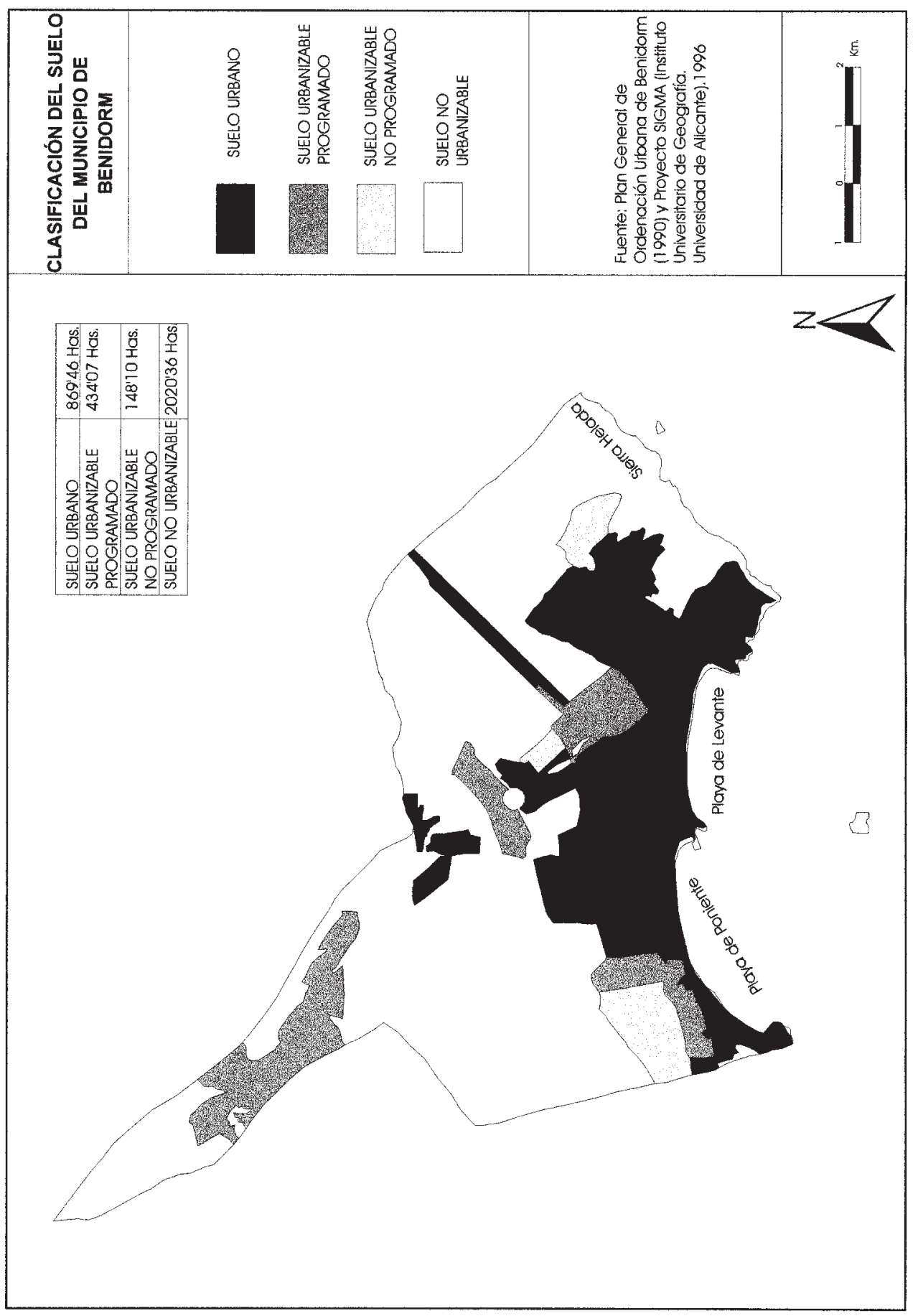




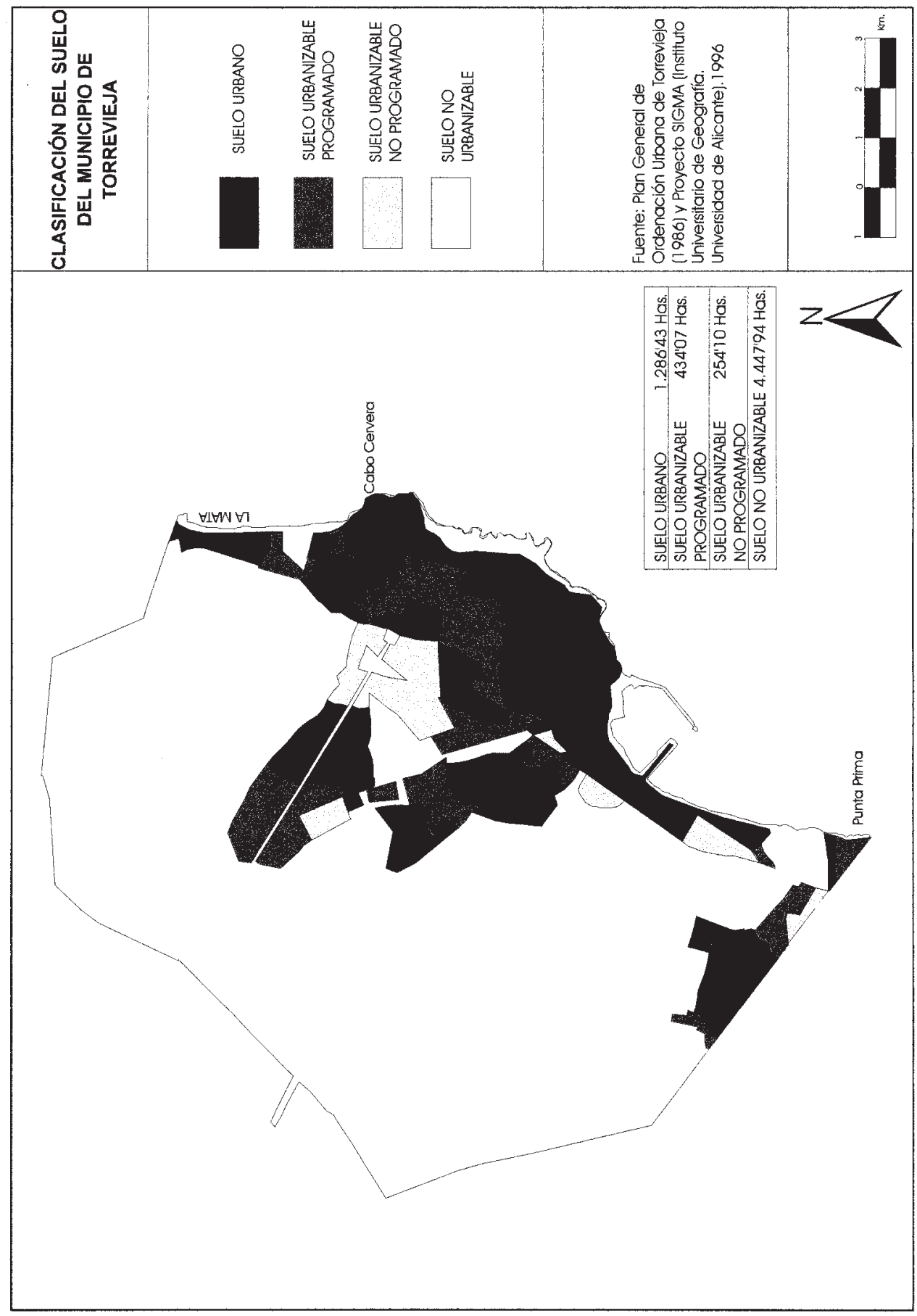




\section{Estacionalidad}

La ruptura del factor estacional en la afluencia de visitantes es, sin lugar a dudas, uno de los retos más importantes a los que debe hacer frente el modelo turístico masivo de sol y playa. La concentración de visitantes en unos pocos meses específicos conlleva una serie de efectos negativos que inciden, muy directamente, como freno en la modernización de un sistema turístico.

El cese de la actividad relacionada con el turismo significa el cierre de multitud de establecimientos orientados al servicio turístico, disminuyendo así, de forma generalmente brusca, la actividad económica de los municipios/destinos, hecho que puede llegar a resultar casi dramático en aquellas áreas donde se da una monoespecialización económica en el turismo. Asimismo, como ya se ha indicado, obliga al sobredimensionamiento de las infraestructuras básicas para conseguir dar respuesta a las demandas producidas en los momentos punta de afluencia de visitantes y provoca, paralelamente, la subutilización de estas infraestructuras durante tres cuartas partes del año, con los consiguientes problemas de mantenimiento, sin olvidar la importante inversión realizada inicialmente, no amortizada.

Benidorm se encuentra entre los destinos turísticos que han conseguido, en gran manera, solucionar el problema de la llegada de visitantes limitada a fechas determinadas. La estrategia de diversificación de la oferta permite captar diferentes segmentos de demanda y ha sido la respuesta de los municipios/destino más dinámicos para mantener sus niveles de actividad en unos umbrales asumibles a lo largo de todo el año. El ejemplo más conocido de estas estrategias, si bien no el único, son las vacaciones del IMSERSO, que permite el mantenimiento de la actividad durante los meses en que los mercados tradicionales permanecen menos activos. Bien es cierto que esa estrategia de diversificación y creación de nuevos productos ha de combinarse, al menos en este caso concreto, con una política de precios adecuada, lo que minimiza el impacto positivo de esas medidas.

Torrevieja, por su parte, debido al predominio de una oferta indiferenciada, escasamente diversificada y totalmente orientada hacia el disfrute del sol y la playa en verano, tiene en la estacionalidad un importante problema.

El consumo urbano de los recursos hídricos resulta un indicador adecuado para el estudio de los flujos estacionales de visitantes. Si bien estos consumos están sometidos a múltiples factores como los hábitos higiénicos, las pérdidas en red o el tipo de alojamiento, reflejan las tendencias en cuanto a la ocupación turística estacional.

En este sentido, tomando como referencia un año tipo (vid. figura 2), los consumos hídricos presentan en ambos municipios un comportamiento estacional, si bien resultan más acusados en el caso de Torrevieja, tal y como queda reflejado en los índices estacionales ${ }^{8}$ con valores de 1'77 en Benidorm y del doble, 3'34, en Torrevieja. El resultado de esta relación entre mes de máximo gasto y mes de mínimo gasto hídrico decreció en el pasado año respecto al quinquenio 1989-1993, en el que este índice alcanzaba la cifra de 2'02 para Benidorm y 3'96 en Torrevieja, sin que ese descenso sea achacable a una minoración de la estacionalidad turística, ya que, como se ha indicado, pueden actuar factores tales como la mejora de las redes de distribución en baja, que reducen la pérdidas por fugas o incluso el éxito de campañas de concienciación ciudadana que eviten el despilfarro de agua.

En lo que se refiere exclusivamente al alojamiento hotelero (figura 3), la ocupación de estas plazas en Benidorm se mantiene por encima del $80 \%$ a lo largo de todo el año, con las

8 Consumo hídrico del mes de máximo gasto dividido entre el consumo generado en el mes de menor gasto. 


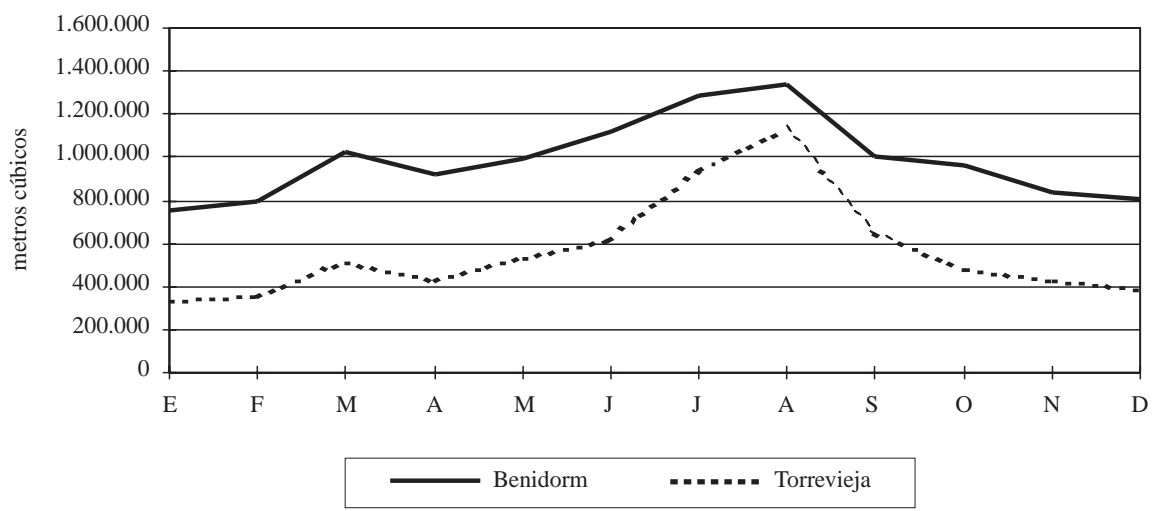

Figura 2. Consumo mensual de agua Benidorm-Torrevieja 1997.

Fuente: Mancomunidad de los Canales del Taibilla y Consorcio de la Marina Baja. Elaboración propia.

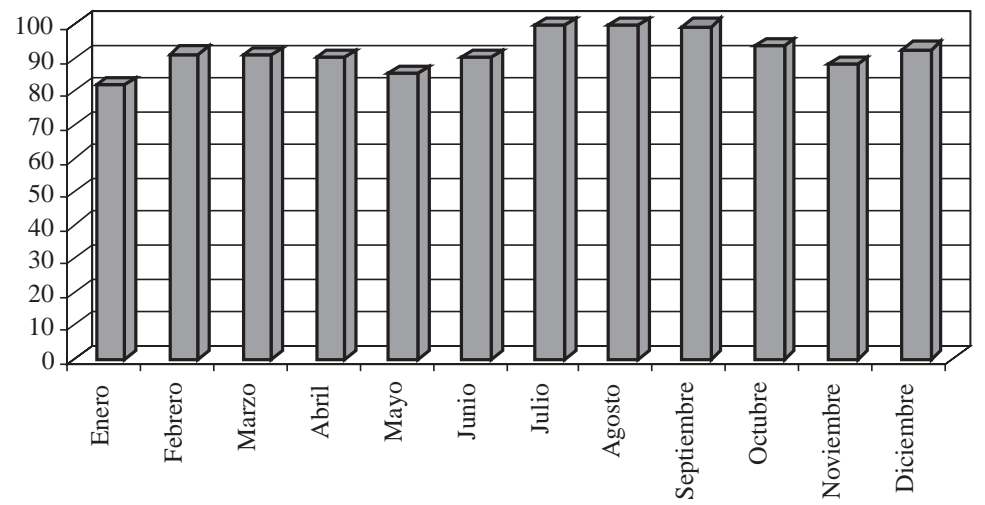

FIGURA 3. Grado de ocupación mensual de los establecimientos hoteleros en Benidorm (1997).

Fuente: Benidorm en cifras, 1998. Ayuntamiento de Benidorm.

lógicas puntas estivales, pero con cifras superiores al 90\% durante, al menos, seis meses al año . El sostenimiento de la actividad por encima de los límites antieconómicos es el resultado de las medidas de creación de nuevos productos anteriormente indicadas, medidas que es posible desarrollar al partir de una situación de producto favorable (oferta de alojamiento de carácter comercial, ofertas de ocio adecuadas, importante conocimiento de la marca Benidorm).

\section{Función comercial y ofertas complementarias}

Las distintas dinámicas turísticas existentes en las poblaciones analizadas se plasman sobre el aparato de servicios instalado, sobre la cantidad, diversidad y calidad del mismo.

9 Porcentajes referidos al volumen de plazas que permanece abierto. 
Las actividades comerciales y de restauración y hospedaje tienen, lógicamente, especial significación en los destinos turísticos (vid. cuadro 9 a 11). Sin embargo, factores como el tipo de demanda turística recibida, la estacionalidad o la propia configuración urbana han propiciado el desarrollo de fórmulas comerciales diferentes para Benidorm y Torrevieja.

En efecto, el aparato comercial de Benidorm posee una mayor calidad y diversidad lo que incluso confiere a la ciudad una de sus imágenes clásicas, debido al elevado de imbricación del mismo en su trama urbana (VERA REBOLLO, 1985). Por el contrario, la extensividad que, se ha venido señalando, caracteriza el desarrollo urbano-turístico torrevejense ha propiciado la aparición de pequeños núcleos comerciales, que dan servicio a las urbanizaciones en su abastecimiento diario, o bien, como señala Vera, grandes superficies ubicadas en las áreas de más reciente crecimiento, e incluso de establecimientos de venta ambulante y mercadillos.

Cuadro 9

NÚMERO I.A.E DE ACTIVIDAD POR AGRUPACIÓN. DIVISIÓN SEXTA

\begin{tabular}{|l|c|c|c|c|c|c|c|c|c|}
\hline & IAE 6.1 & IAE 6.2 & IAE 6.3 & IAE 6.4 & IAE 6.5 & IAE 6.6 & IAE 6.7 & IAE 6.8 & IAE 6.9 \\
\hline BENIDORM & 99 & 2 & 19 & 390 & 1129 & 139 & 871 & 168 & 79 \\
\hline TORREVIEJA & 95 & 1 & 16 & 210 & 426 & 181 & 488 & 25 & 55 \\
\hline
\end{tabular}

Fuente: Listado de Número de IAE por Municipio y Epígrafe. Cámara Oficial de Comercio, Industria y Navegación de Alicante, 1997.

Elaboración propia.

\section{Denominación de las Agrupaciones del IAE. División 6.}

6.1. Comercio al por mayor.

6.2. Recuperación de productos.

6.3. Intermediarios del comercio.

6.4. Comercio al por menor de productos alimenticios, bebidas y tabaco, realizado en establecimientos permanentes.

6.5. Comercio al por menor de productos industriales no alimenticios realizado en establecimientos permanentes.

6.6. Comercio mixto o integrado: comercio al por menor fuera de un establecimiento comercial permanente (ambulancia, mercadillos y mercados ocasionales o periódicos). Comercio en régimen de expositores en depósito y mediante aparatos automáticos. Comercio al por menor por correo y catálogo de productos diversos.

6.7. Servicios de alimentación

6.8. Servicios de hospedaje

6.9. Reparaciones

Asimismo, esas diferencias de orden cualitativo y cuantitativo se manifiestan en los establecimientos de dispensación de comidas y bebidas (cuadros 10 y 11).

Cuadro 10

NÚMERO DE RESTAURANTES Y PLAZAS EN TORREVIEJA Y BENIDORM DISTRIBUIDOS SEGÚN CATEGORÍAS

\begin{tabular}{|c|c|c|c|c|c|c|c|c|}
\hline & \multicolumn{2}{|c|}{$1^{\mathrm{a}}$} & \multicolumn{2}{|c|}{$2^{\mathrm{a}}$} & \multicolumn{2}{|c|}{$3^{\mathrm{a}}$} & \multicolumn{2}{|c|}{$4^{\mathrm{a}}$} \\
\hline & $\mathbf{N}^{0}$ & PLAZAS & $\mathrm{N}^{0}$ & PLAZAS & $\mathrm{N}^{0}$ & PLAZAS & $\mathbf{N}^{0}$ & PLAZAS \\
\hline BENIDORM & 1 & 80 & 3 & 102 & 170 & 9.122 & 190 & 8.936 \\
\hline TORREVIEJA & 0 & 0 & 2 & 80 & 106 & 6.446 & 173 & 9.061 \\
\hline
\end{tabular}

Fuente: Oferta turística municipal y comarcal, 1997. Agencia Valenciana del Turismo.

Elaboración propia. 
Cuadro 11

NÚMERO DE CAFETERÍAS Y BARES SEGÚN CATEGORÍAS EN BENIDORM Y TORREVIEJA

\begin{tabular}{|l|c|c|c|c|c|}
\hline & TRES TAZAS & DOS TAZAS & UNA TAZA & $\begin{array}{c}\text { BARES CATEGORÍA } \\
\text { ESPECIAL }\end{array}$ & $\begin{array}{c}\text { OTROS CAFÉS Y } \\
\text { BARES }\end{array}$ \\
\hline BENIDORM & 2 & 52 & 102 & 69 & 46 \\
\hline TORREVIEJA & 4 & 12 & 9 & 26 & 273 \\
\hline
\end{tabular}

Fuente: Listado del Impuesto de Actividades Económicas, 1997. Cámara Oficial de Comercio, Industria y Navegación de Alicante.

Elaboración propia.

Elemento singular en la oferta de servicios turísticos al consumidor es la denominada oferta turística complementaria, la oferta de ocio desarrollada paralelamente a los recursos básicos y al alojamiento. En el actual proceso de reposicionamiento de los destinos turísticos clásicos, originado por los cambios en la tendencia de la demanda turística internacional, la oferta complementaria se configura como uno de los principales argumentos de diferenciación y diversificación de los mismos.

Independientemente de la importancia de elementos de oferta como los correspondientes a la categoría de ocio y diversión constituida por bares, pubs o discotecas, de indudable interés para determinados grupos de demanda, y que generan incluso de importantes flujos con origen en diversos puntos de la provincia, mayor atención merecen equipamientos de ocio con una impronta turística y territorial superior.

Un primer nivel lo constituyen aquellos piezas de oferta, que podrían definirse como ofertas complementarias clásicas, instaladas durante los años ochenta y que fueron utilizadas como argumento de cualificación de los destinos, si bien, en muchas ocasiones, no representaban más que intento de mantener las dinámicas de los años precedentes mediante la inserción de elementos favorecedores de una presunta, y rara vez alcanzada, mejora cualitativa del destino. En este grupo se incluyen ofertas del tipo náutico-deportivo, campos de golf o parques acuáticos, con especial significación para los dos primeros.

En los casos de Torrevieja y Benidorm, cabría señalar entre este tipo de instalaciones la Marina Internacional de Torrevieja (con 860 amarres), que posee claras implicaciones inmobiliarias, el Real Club Náutico de Torrevieja (460 puestos de amarre) y un parque acuático. En Benidorm, las instalaciones náutico deportivas se limitan al Club Náutico de Benidorm que cuenta con 100 amarres. Asimismo, existe un parque acuático, complementado con un parque dedicado a especies animales exóticas.

Son otros los aspectos donde verdaderamente se reflejan las importantes diferencias que, en cuanto a capacidad de generación de ofertas de ocio, existen entre Benidorm y Torrevieja.

Ambos municipios han organizado su espacio urbano a través de la consolidación del turismo como la principal actividad económica local. Sin embargo, en el caso de Benidorm la influencia del turismo como actividad con capacidad de organizar un territorio se extiende más allá de los límites municipales, mediante la incorporación de recursos externos al municipio, como fórmula de complementariedad y diversificación de sus propias ofertas desarrollando una estrategia de incorporación del traspaís a los productos turísticos litorales, en un proceso que cuenta con importantes connotaciones territoriales por cuanto incide en la reestructuración de un espacio subregional. Es el caso de poblaciones como 
Guadalest, Callosa d'en Sarrià, Jalón o Benissa que, como se ha señalado, mantienen convenios de colaboración con Benidorm para la promoción de sus recursos ${ }^{10}$. Asimismo, Benidorm ha incluido entre su oferta turística, con la organización de excursiones en autocar, recursos ubicados, no ya en su interior inmediato, sino incluso fuera de la provincia de Alicante ${ }^{11}$.

Por último, otro ejemplo de ese potencial de captación y creación de ofertas de ocio de Benidorm será la instalación del parque temático Terra Mítica en las inmediaciones de esta ciudad. Así, Benidorm se incorporará a una de las principales tendencias que, en la década de los años noventa, se están operando sobre la oferta turística, la tematización. Las expectativas de la administración turística valenciana se centran en que este proyecto se constituya en el gran elemento de oferta complementaria de Benidorm y su área de influencia turística, además de considerar que Terra Mítica permitirá la captación de nuevos segmentos de demanda, ajenos hasta el momento a este destino.

\section{Estructura demográfica}

Se ha considerado la estructura de la población como el quinto indicador de las diferencias entre las poblaciones de Benidorm y Torrevieja, entre un modelo turístico concentrado y un modelo vacacional extensivo. Como elemento común a ambos casos, el proceso de despegue demográfico conocido en estas dos ciudades se relaciona con la implantación y desarrollo de la actividad turística en su territorio. Las divergencias entre ambos municipios se manifiestan en aspectos tales como el momento en que se produce el despegue demográfico, estrechamente vinculado con el inicio de la actividad turística, los ritmos de crecimiento y estructura demográfica heredada.

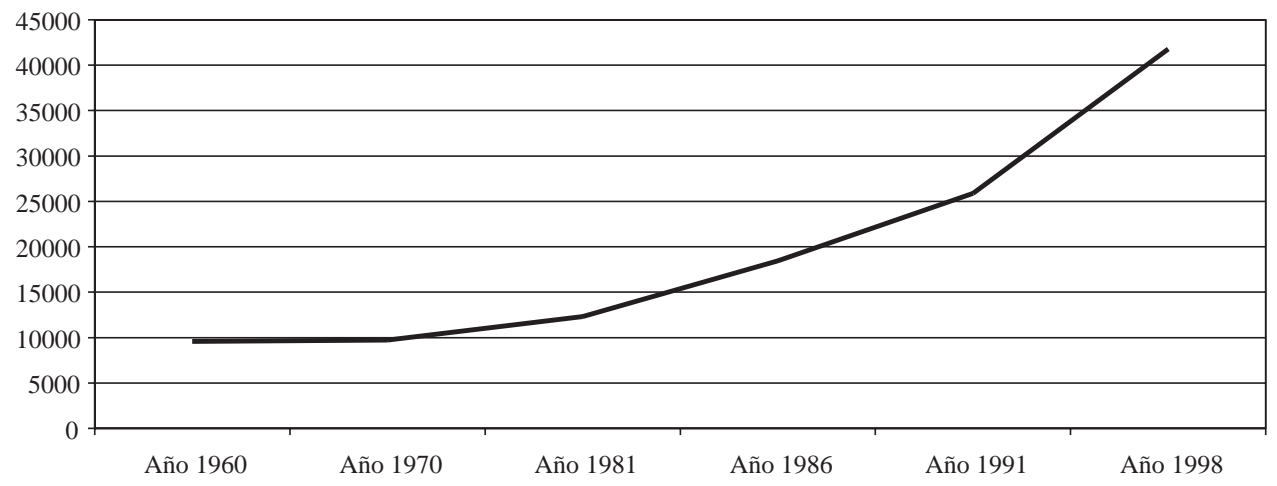

FiguRA 4. Evolución de la población empadronada en Torrevieja. (1960-1998).

10 La comarca de la Marina Baja, junto con otros espacios subregionales de Grecia e Italia, ha sido objeto de un estudio cofinanciado por la Unidad de Turismo de la Dirección General XXIII de la Unión Europea, el denominado Proyecto SMART (Strategic Management Actions Relating to Tourism) por el cual se analizaron las potencialidades turísticas del traspaís en áreas con importantes desarrollos turísticos litorales y sus posibles complementariedades.

11 Es el caso de la ciudad de Murcia, como oferta de ciudad de monumental. La propia ciudad de Alicante se incorpora como «ciudad de compras». 


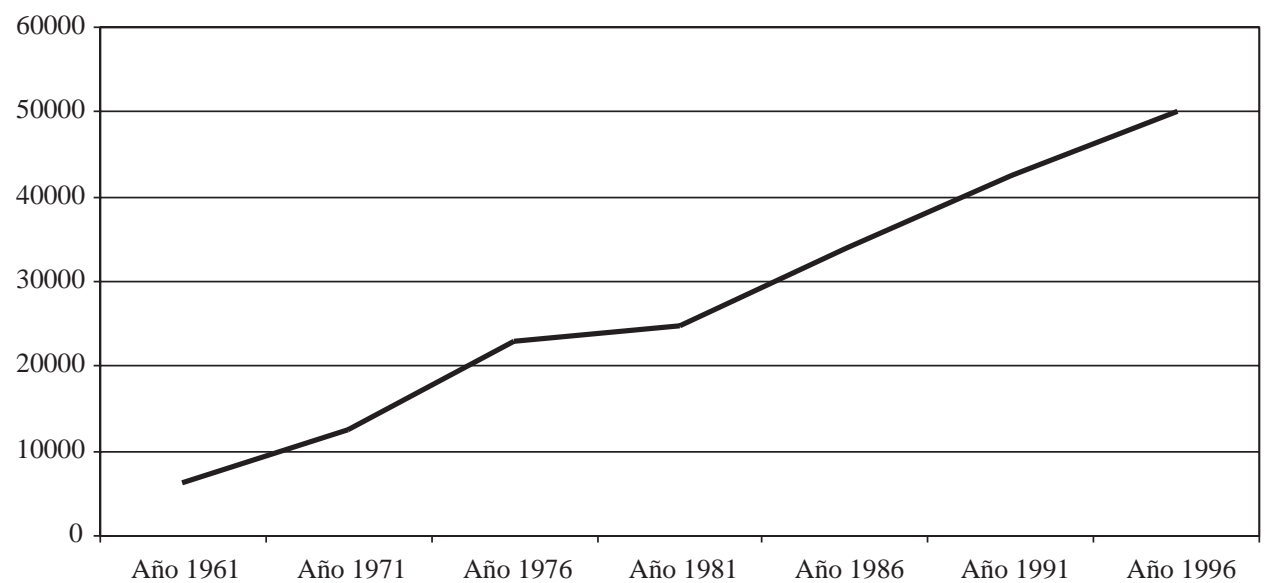

FiguRA 5. Evolución de la población empadronada en Benidorm. (1961-1996).

Fuente: Ayuntamientos de Torrevieja y Benidorm.

El despegue demográfico de Benidorm se produce con anterioridad al de Torrevieja. En el primer caso, ya en la década de los años 60 comienza el crecimiento de la población que se mantiene, de forma sostenida, hasta la actualidad. En Torrevieja ese despegue poblacional sucede a partir de la mitad de la década de los ochenta, coincidiendo con el gran desarrollo urbano-turístico que supuso la consolidación como el principal destino vacacional valenciano. En oposición al crecimiento homogéneo y sostenido de Benidorm, el crecimiento demográfico torrevejense se produce de manera muy intensa, pues en los últimos 10 años ha visto incrementados sus efectivos demográficos en un $225 \%$. En efecto, las corrientes migratorias propiciadas por el turismo han supuesto la modificación de las estructuras sociodemográficas de ambas poblaciones, quebrando las tendencias negativas de épocas anteriores al desarrollo turístico, con tasas de crecimiento superiores a las generadas por la industria en otras ciudades de la provincia (VERA REBOLLO, 1993).

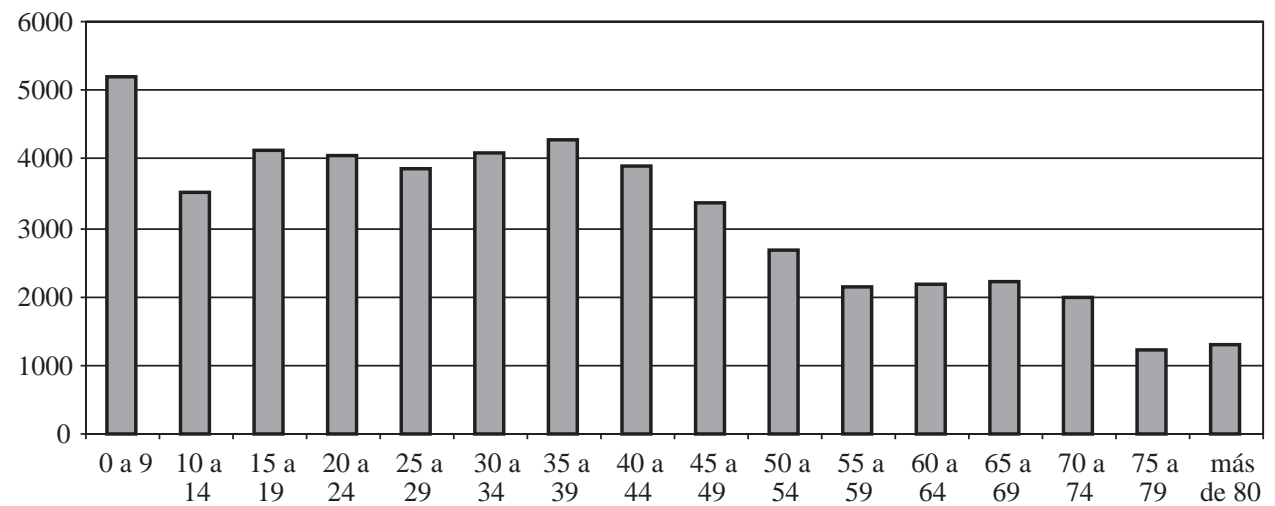

FIGURA 6. Estructura de la población por edades. Benidorm. 
Por lo que respecta a la estructura por edades de la población, Benidorm presenta un importante contingente joven, en edad activa, debido precisamente a esos procesos inmigratorios provocados por la existencia de un importante mercado de trabajo, mientras en Torrevieja sobresale el considerable peso de los grupos de tercera edad (figuras 6 y 7). En este último caso, la notable concurrencia de estas cohortes unido a una cifra de más de diez mil habitantes extranjeros empadronados (figura 8), manifiesta la tendencia hacia la conversión de Torrevieja en destino atractivo como residencia invernal, como ocurre en algunas poblaciones de la comarca de la Marina Alta. Asimismo, destaca la escasa presencia de población autóctona, hecho acentuado en Benidorm donde únicamente el 10\% de la población es originaria de la propia ciudad y el $50 \%$ procede de otras Comunidades Autónomas (fundamentalmente Andalucía y Centro peninsular).

Especial interés posee la política de fomento del empadronamiento puesta en marcha por el ayuntamiento de Torrevieja, medidas que justifican el espectacular aumento de población ocurrido entre 1991 y 1998. Esta política, orientada a disminuir las diferencias entre la población de hecho y la de derecho y, consecuentemente, los importantes problemas de orden financiero asociados, se basa en tres tipos de medidas básicas:

- subvención de medio millón de pesetas a los nuevos matrimonios empadronados, con obligación de un periodo de residencia mínimo en el municipio. Se consigue así el traslado de un contingente poblacional que reside en localidades próximas y trabaja en Torrevieja, al tiempo que se rejuvenece la pirámide de edades.

- exención de impuestos municipales a personas de la tercera edad, con lo que se consigue el empadronamiento de una población residente, destacando la presencia de extranjeros.

— se pondrá en práctica la gratuidad del transporte público para los empadronados.

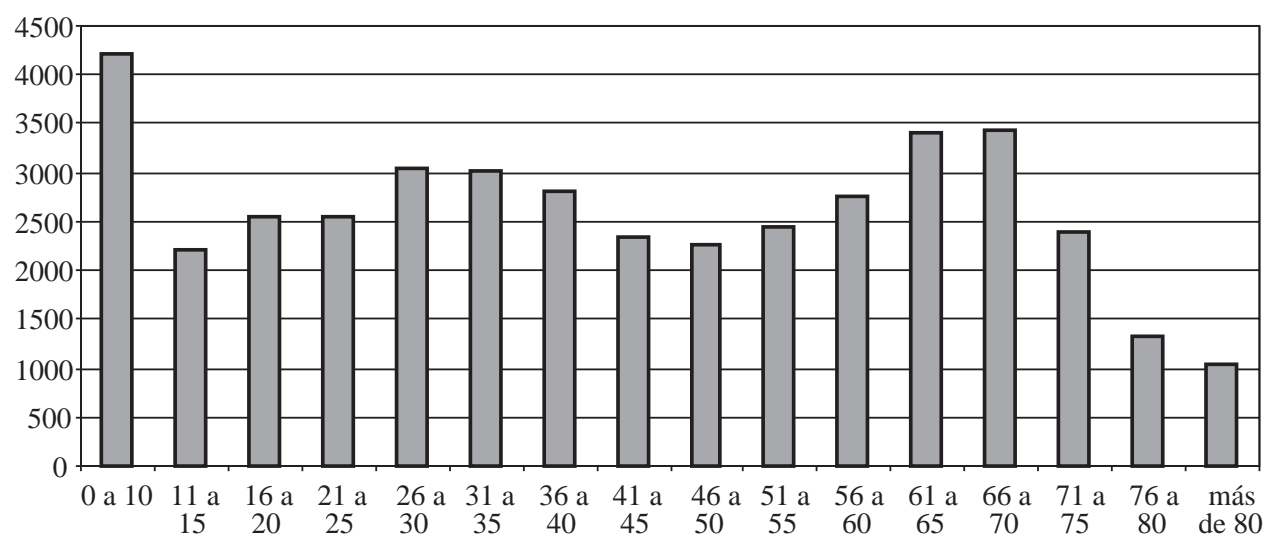

Figura 7. Estructura de la población por edades. Torrevieja.

Fuente: Ayuntamientos de Benidorm y Torrevieja.

Por último, los diferentes modelos de desarrollo turístico inciden también sobre la estructura socioprofesional de la población. Los servicios es el sector con más activos tanto en Torrevieja como en Benidorm, y adquieren carácter prácticamente de monoespecialización en el segundo caso, mientras que en caso Torrevieja el subsector de la construcción acoge a más del $20 \%$ de la población activa. 


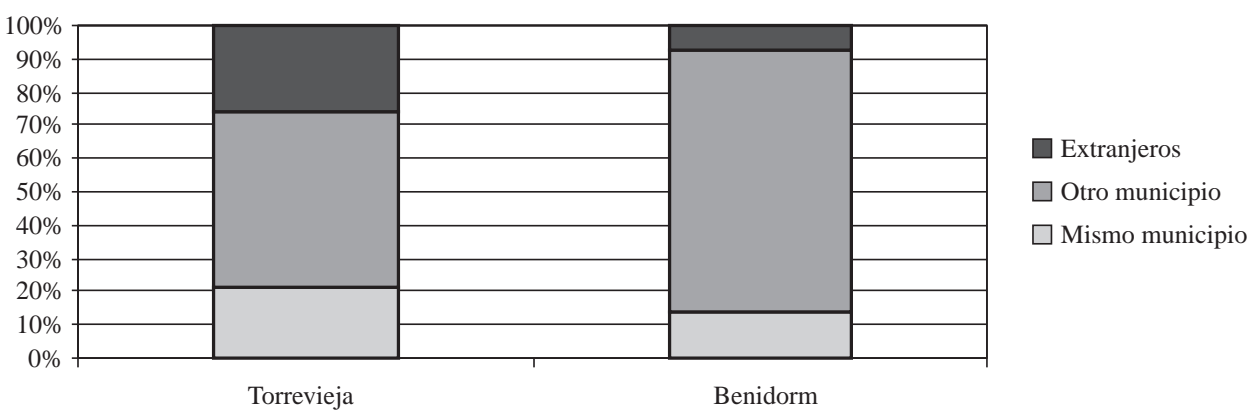

FIGURA 8. Distribución relativa de la población empadronada según origen.

Fuente: Ayuntamientos de Benidorm y Torrevieja.

\section{Conclusiones y propuestas de actuación}

La diversidad e importancia de competencias municipales que afectan al desarrollo de la actividad turística exigen la comprensión global del municipio como destino turístico y obligan a que sea la local la escala básica de análisis de las relaciones entre turismo y territorio.

La explotación turística de los atractivos sol y la playa ha tenido como resultado la concreción de variados modelos territoriales-turísticos locales así como de diversas fórmulas de desarrollo de la actividad. En el presente trabajo se han destacado dos de estos modelos, quizá los más intensivos en el consumo de recursos territoriales. En primer lugar un modelo que se ha denominado concentrado, ejemplificado por la ciudad de Benidorm, y un segundo, definido como extensivo, puesto de manifiesto en el caso de Torrevieja. Ambas poblaciones tienen en el turismo su principal actividad económica y se incluyen dentro de del genéricamente denominado modelo turístico masivo de sol y playa. Sin embargo, las bases preturísticas existentes (estructura de la propiedad de la tierra), los agentes económicos que se han erigido en protagonistas del proceso de creación de nuevas bases económicas y modificación de los usos del suelo, el grado de planificación o espontaneidad con que han contado esos procesos y la endogeneidad o dependencia de los elementos actuantes han sido los factores que justifican las diferencias entre ambos modelos turísticos.

Estas desigualdades, que se ven plasmadas en los diferentes componentes de la oferta turística (alojamiento, ofertas complementarias, aparato comercial y de prestación de servicios privados), en las estructuras sociodemográficas locales o en la propia configuración urbana, han tenido como consecuencia la captación de diferentes segmentos de demanda turística - vacacionistas mayoritariamente españoles, alojados en viviendas en régimen de alquiler o propiedad en el caso de Torrevieja y turistas de más diversa procedencia, repartidos al cincuenta por ciento entre extranjeros y españoles, con importante presencia de la oferta de alojamiento hotelero, en el caso de Benidorm- que demuestran hábitos de ocio y consumo plenamente diferenciados.

El breve diagnóstico efectuado sobre la situación del turismo en los dos municipios estudiados pone de manifiesto, de forma clara y contundente, dos realidades turístico territoriales muy distintas. Por tanto, los problemas presentes en cada uno ellos son muy 
diversos, y la viabilidad futura de la actividad turística local dependerá de estrategias y actuaciones distintas.

De esta manera, el diseño de las actuaciones en materia territorial-turística ha de tener, obligatoriamente, en Torrevieja una orientación de reacondicionamiento del espacio turístico consolidado, donde los criterios de cualificación del espacio y la sostenibilidad futura de la actividad son los argumentos que han de guiar las líneas básicas a seguir. Indiscutiblemente, el ejemplo prototípico de este tipo de acciones es el del conocido municipio mallorquín de Calvià.

Por tanto, la primera actuación a consolidar es el cese en el crecimiento cuantitativo del número de plazas, que en esta localidad son en forma de viviendas. Tras el espectacular crecimiento de finales de la década de los años 80 y posterior parón en la actividad inmobiliaria, se asiste en los últimos tiempos a una reactivación de la misma, que puede suponer, de mantenerse los ritmos de crecimiento, la definitiva colmatación urbanística municipal ${ }^{12}$. Mayores dificultades puede representar la redefinición cualitativa de la oferta de alojamiento instalada. La abrumadora presencia de un tipo de alojamiento, que se ha definido como de carácter no comercial, supone un notable problema en estas tareas de reconfiguración turística. Las importantes inercias producidas por el modelo cuantitativo de creación de espacio turístico, impiden la inclusión de gran parte de ese parque de viviendas en circuitos de distribución comercial adecuados.

Entre los argumentos territoriales que se plantean como ineludibles para afrontar la citada reconversión turística que permitan la sostenibilidad de la actividad, destacan los aspectos ambientales, básicos en la recualificación de los espacios turísticos maduros para adoptar fórmulas competitivas ante las nuevas exigencias de la demanda, entre las que destaca un importante auge de la conciencia ambiental ${ }^{13}$, y que, en el caso de Torrevieja, se han visto hipotecados por el crecimiento urbano-turístico, únicamente limitado por la disponibilidad del suelo. Ejemplo diáfano de la falta de consideración hacia los recursos ambientales lo constituye el Parque Natural de las Salinas de Torrevieja y La Mata, espacio de innegable interés natural, con considerables potencialidades turísticas, y que fue durante mucho tiempo ignorado, constituyendo la trasera de urbanizaciones. Este espacio protegido representa una de las principales oportunidades de cualificación, a través de la vía de la diferenciación, del producto turístico torrevejense, partiendo de una adecuada valoración de los atractivos intrínsecos y los pertinentes estudios de capacidad de carga.

En este sentido, parece detectarse un cambio de tendencia en la política municipal, como demuestra la realización de varias actuaciones que inciden en una mejora cualitativa del medio ambiente urbano. Así, cabe indicar el soterramiento de los contenedores de basura en el interior de la ciudad, la mejora paisajística realizada en el acceso a la población mediante una operación de diseño, disminuyendo antiestéticas escombreras que se sustituyen por espacios ajardinados o la definitiva conexión a la red de saneamiento de aguas residuales de prácticamente todas las urbanizaciones, como acciones adecuadas que mejoran considerablemente la imagen urbana del destino.

Especial atención merece la actuación a realizar en el espacio conocido como las Eras de la Sal. En efecto, el denominado Plan Director de las Eras de la Sal pretende recuperar para su uso público un espacio privilegiado, ubicado entre el Club Naútico y el Puerto Deportivo Marina Internacional de Torrevieja, con un uso vinculado con la tradicional actividad salinera y cuyo proyecto original data del último cuarto del siglo XVIII. Esta

12 Entre 1991-1998 se ha pasado de 44.000 a 61.000 viviendas de uso estacional.

13 Torres Bernier (1996) destaca entre las grandes tendencias de la nueva demanda turística la sensibilización por los aspectos medioambientales. 
iniciativa, auspiciada por el Ayuntamiento de Torrevieja y el Instituto Municipal de Cultura Joaquín Chapaprieta y que cuenta con la participación de la Universidad de Alicante y la Universidad Politécnica de Valencia, se enmarca dentro de las actuaciones de recomposición de bordes marítimos en áreas degradadas y supone un cambio de uso de esta pieza urbana y la inserción de una tipología arquitectónica acorde con el entorno. Asimismo, conviene señalar que en el caso del Plan Director de las Eras de la Sal se han abierto cauces de participación ciudadana adecuados que permitan hacer partícipe de este proyecto a la sociedad local, incluso colaborando en la aportación de ideas en cuanto a la asignación de los usos que se darán a este sector.

Finalmente, resulta necesario incidir en otros muchos aspectos que suponen una pérdida del atractivo y competitividad turística de Torrevieja. Cuestiones como la mejora de la escena urbana, desdensificación, necesidad de equipamientos y servicios para una creciente población de la tercera edad asentada en la ciudad, creación de espacios libres o solventar los problemas de interconexión entre las urbanizaciones, requieren de una respuesta rápida y eficaz. En este sentido, parecería adecuada la redacción de un nuevo Plan General de Ordenación Urbana (el vigente data de 1986), que recoja los nuevos supuestos demográficos, territoriales y turísticos vigentes.

En el caso de Benidorm, las estrategias de sostenimiento futuro de la actividad turística han de incidir en la vía ya iniciada de la diversificación del producto mediante la inserción de nuevas ofertas. Parece adecuado continuar la colaboración con municipios interiores como estrategia de diversificación de la oferta. En este sentido, la incorporación de nuevos recursos en la configuración de productos novedosos supondría un importante paso adelante para el mantenimiento del liderazgo ostentado por la ociurbe de la Marina Alta.

Respecto a la construcción en Benidorm del parque temático Terra Mítica, es necesario aprovechar las importantes inercias generadas por la instalación de este tipo de ofertas. Además de las innegables ventajas asociadas al parque en sí mismo, aspectos como las importantes inversiones en infraestructuras o la captación de nuevos segmentos de demanda supondrán efectos inducidos que será necesario aprovechar. La creación de Port Aventura, el parque temático de la Costa Daurada, supuso el alargamiento de la temporada turística, la llegada de segmentos de demanda de corta estancia, el estímulo a la creación de nuevos productos recreativos o la mejora general de la imagen de los núcleos turísticos del área, no únicamente el caso de Salou y Vila-Seca, municipios donde se asienta el parque de Anheuser Busch (VERA REBOLLO; LÓPEZ PALOMEQUE; MARCHENA GÓMEZ y ANTON CLAVÉ, 1996).

Respecto a la oferta de alojamiento, resulta aconsejable optar por el freno al crecimiento indiscriminado de plazas de alojamiento y limitarlo exclusivamente a actuaciones que sean cualitativamente oportunas. Asimismo, resulta necesario incrementar el ritmo de legalización de las plazas ofertadas en apartamentos, de manera que permitiese una elevación del nivel cualitativo de éstas y una mayor optimización de las mismas.

Finalmente, señalar la necesidad de coordinación entre diferentes escalas de la administración turística. Si bien la escala local se comprende como básica para el análisis de la actividad turística, las nuevas realidades turísticas que vienen configurándose en los últimos años justifican la actuación desde otros niveles —escalas intermedias, regionalAspectos tales como la complementariedad de recursos o la importancia cobrada por los factores ambientales justifican estos enfoques. 


\section{Bibliografía}

AGÈNCIA VALENCIANA DEL TURISME (1997): Oferta turística municipal y comarcal 1997. Generalitat Valenciana.

BUTLER, R.W. (1980): «The concept of a tourist area cycle of evolution: implications for management of resources» en Canadian Geographer, 24 (1) pp. 5-12.

CONSULTUR, S.A. Estudio de los Planes de Excelencia Turística.

GENERALITAT VALENCIANA. Ley 3/1998, de 21 de mayo, de Turismo de la Comunidad Valenciana.

TORRES ALFOSEA, F.J. (1995): Aplicación de un sistema de información geográfica al estudio de un modelo de desarrollo local. Crecimiento urbano turístico de Torrevieja. Universidad de Alicante e Instituto Municipal de Cultura Joaquín Chapaprieta. 103 pp.

TORRES BERNIER (1996): «Las megatendencias en el sector turístico», en Turismo y promoción de destinos turísticos: implicaciones empresariales. Luis Valdés y Agustín Ruiz (Coord.) Universidad de Oviedo. pp. 11-20.

VERA REBOLLO, J.F. (1995): «Municipio y turismo», en ¿España, un país turísticamente avanzado? I Congreso de la AECIT. Marbella. AECIT e Instituto de Estudios Turísticos, pp. 91-114.

VERA REBOLLO, J.F.; CRUZ OROZCO, J.; BAÑOS CASTIÑEIRA, C.J. (1995): «Turismo y organización del territorio: desajustes de un modelo de implantación y nuevas estrategias» en Cuadernos de Geografía n 58 Políticas Territoriales Valencianas, Departamento de Geografía, Universidad de Valencia, pp. 439-474.

VERA REBOLLO, J.F.; LÓPEZ PALOMEQUE, F.; MARCHENA GÓMEZ, M.J.; ANTON CLAVÉ, S. (1997): Análisis Territorial del Turismo. Barcelona. Ariel. 443 pp. 
